\title{
Feasibility Analysis of the Power Supply Model Using Solar PV for the Public Lighting System in Hanoi
}

\author{
Hang Le Thi Thur ${ }^{1 *}$ and Dong Ngo Nguren ${ }^{2}$ \\ ${ }^{1}$ Institute of Energy Science, Vietnam Academy of Science and Technology, Vietnam \\ ${ }^{2}$ Vietnam Electricity Group, Vietnam
}

\begin{abstract}
Public lighting is an essential service in today's cities, towns, and highways, including improving public safety and reducing traffic accidents. Public lighting could consume up to $40 \%$ of the energy budget of the local governments. Therefore, the technical innovations related to public lighting always bring significant value to municipal governments. In Vietnam, the public lighting in big cities account for $25 \%$ of the total power consumption. The solutions to reducing electricity consumption for public lighting are also of interest to domestic and foreign organizations, including the use of on-site energy such as wind and solar energy. In this paper, on the basis of the current state of the public lighting system and the potential of solar energy in Hanoi, the authors have roughly calculated the technical and economic efficiency of power supply solutions using solar energy in public lighting. The proposal of solving the power supply problem, by using solar energy in public lighting in Hanoi is another result of the paper.
\end{abstract}

Keywords: public lighting, solar PV, solar potential, power supply system, Vietnam

\section{INTRODUCTION}

Public lighting is one of the most important items in the public sector. Public lighting has many benefits, such as promoting economic growth, improving safety through reducing rates of crime and traffic accidents, and ultimately enhancing the city aesthetics.

According to World Bank [1], the public lighting accounts for $4 \%$ of global electricity consumption - roughly the same amount of Germany. Cities are among the world's largest energy consumers, accounting for more than $70 \%$ of total electricity consumption and about two-thirds of global greenhouse gas emissions. The public lighting system contributes significantly to urban energy consumption, up to $40 \%$ of the electricity budget $[1,2]$.

Public lighting is also expensive to operate and maintain. In India, electricity supply and maintenance costs for street lighting cost about 5 to $10 \%$ of the budget in big cities and up to $20 \%$ in smaller cities [3]. In Canada, electricity consumption and operating costs for public lighting are

${ }^{*}$ Corresponding author: lehang@ies.vast.vn

Received: 8 May 2021 Accepted: 25 May 2021 Published: 4 Jun 2021

Journal of Asian Energy Studies (2021), Vol 5, 14-21, doi:10.24112/jaes.050002 
quite high due to a large number of lighting systems and the remoteness of some cities [4]. For example, Greenstone, a small town in northwestern Ontario, is up to three hours by car from the nearest repair team, increasing costs and causing delays in receiving and completing services for the lighting systems there. In Mexico, the cost of public lighting accounts for $18 \%$ of the electricity consumed, making up a significant portion of the local budget [5]. In the Philippines, electricity costs for public lighting in some municipalities amount to $65 \%$ of the annual electricity costs, accounting for $5 \%$ of the total annual local budget [6]. In Brazil, public lighting covers for more than $4 \%$ of the country's total energy consumption and the energy costs for public lighting is the second highest in the budgets of most municipalities [7].

As a result, the energy-efficient solutions for public lighting deliver significant value to municipalities and utilities, including reduced operating and maintenance costs as well as investment costs in generation, transmission, and distribution.

In Vietnam, the electricity for public lighting accounts for about $25 \%$ of the country's electricity consumption [8,9]. The main reason comes from lighting standards that are no longer suitable with the current conditions, especially in big municipalities. According to the most recent resolution of the Vietnam government on the urban classification [10], the rate of main streets to be illuminated is $100 \%$ in class-I municipalities, approximately $96 \%$ in class-II municipalities, around $90 \%$ in class-III municipalities; and about $80 \%$ in the remaining municipalities. The class-I municipalities include centrally-controlled cities, the class-II or class-III municipalities are provincially-controlled cities or municipality-controlled cities, the remaining municipalities are towns and townships. However, public lighting planning in Vietnam has not been given due attention. Many planning documents have been published, but the lighting content is only briefly mentioned, and there is no specific guidance on the content of urban lighting planning [10,11]. In particular, the current planning documents only mention the ratio of public lighting in large and small streets, but have not mentioned the required lighting standards. Some regulations on new construction and renovation of public lighting systems are stated in the National Technical Regulations but only very briefly [12]. Lighting quality improved after the project Vietnam Energy Efficiency Public Lighting was started in 2011, but it has not met the requirements and criteria in terms of quantity and quality of lighting, low lighting efficiency, and high power consumption [8,9].

In such a context, Vietnam has adopted a number of solutions to reduce electricity consumption in the local public lighting system [9]. The first solution is to reduce the number of active lights from 23:00 to the next morning, such as turning off one-third to two-third of the total number of active lights and turning off all decorative lights. The second is to reduce lighting power in range of $25 \%$ to $40 \%$ of each light from $23: 00$ to the next morning, or adapt the ballast at two power levels including high power level from 18:00 to 23:00 and low power level after 23:00. It can be seen that these solutions have temporarily solved the wasteful power consumption of the local public lighting. However, these solutions can cause uneven lighting density, decrease the aesthetics of the route, reduce the safety of vehicles in traffic, and problems with security. In addition, the overvoltages often occur at night when the reduced power demands can increase power consumption and shorten the light life.

In addition to the mentioned solutions, the use of renewable energy sources to power public lighting systems, especially solar energy, has been applied by many countries around the world [13-15]. However, the exploitation and use of these energy sources depend greatly on their local potential.

The Orientation of Urban Lighting in Vietnam to 2025 [16] has clearly affirmed that "urban lighting development must follow urban construction and development plans; step by step modernizing, improving quality efficiency, innovating technology, using renewable energy in urban lighting to save energy, contributing to the socio-economic development of Vietnam". The 
application of the power supply model using solar energy for public lighting not only meets the power demand for lighting, but also improves the community's awareness of energy-saving and environmental protection.

In this paper, the authors have investigated the current state of the public lighting system as well as the solar energy potential in Hanoi. The paper also presents preliminary results of technical and economic benefits for the use of solar energy in public lighting in Hanoi. Finally, there is a proposal for a technology solution to supply electricity using solar energy for public lighting in Hanoi.

\section{Current Status of Public Lighting System in Hanoi}

In Hanoi, the public lighting system has had more than 40 years of investment and development $[8,9]$, see Figure 1 and Figure 2. Moreover, in the past 10 years, the development scale and speed of the public lighting system expansion has been very large. The public lighting system in Hanoi is now has up to 200,000 lights of all kinds, with a total capacity of up to $27 \mathrm{MW}$ in 30 districts.

Currently, the public lighting system in Hanoi uses high pressure lights of metal halide, sodium and mercury with the power levels of $70 \mathrm{~W}, 125 \mathrm{~W}, 150 \mathrm{~W}, 250 \mathrm{~W}$, and $400 \mathrm{~W}[8,9]$. The rate minimum illumination is $98 \%$ in the big streets, $95 \%$ in the small street, and $98 \%$ in the parks. The operating time of the public lighting system is adjusted according to the season, from $6: 30 \mathrm{pm}$ to $5 \mathrm{am}$ in the summer, and from 5:30 pm to $6 \mathrm{am}$ in the winter.



Figure 1: Public lighting in a busy road in Hanoi

\section{Assessments of Potential of Solar Energy in Hanoi}

Due to a favorable geographical location, Vietnam is considered to have high solar energy potential with a lot of sunlight hours in a year $[17,18]$. Accordingly, the average solar potential for the whole country ranges from 3.5 to $5 \mathrm{kWh} / \mathrm{m}^{2}$ in a day and the average sunlight hours ranges from 1600 to 2600 hours per year.

In Hanoi, the annual average solar potential is $3.95 \mathrm{kWh} / \mathrm{m}^{2}$ in a day with an average of 145 sunlight hours in a month [17], see Figure 3 and Figure 4. Accordingly, the month with the lowest solar potential is February with an average radiation of $2.4 \mathrm{kWh} / \mathrm{m}^{2}$ in a day and 49 sunlight 


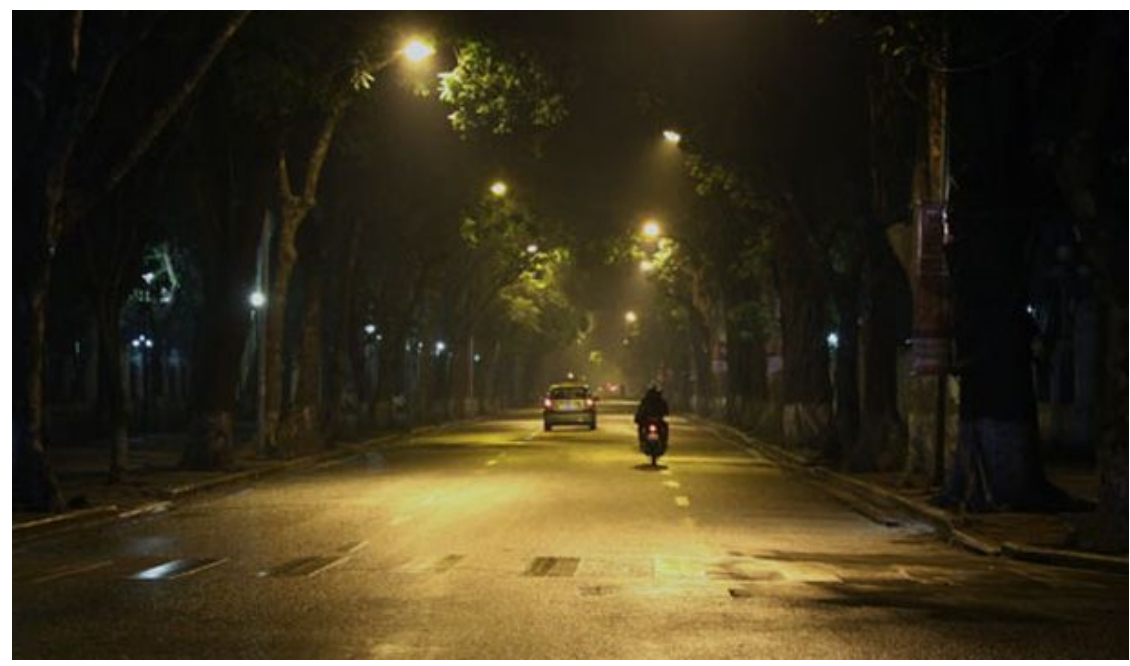

Figure 2: Public lighting in a small street in Hanoi

hours, and the month with the highest potential is July with average radiation of $5.59 \mathrm{kWh} / \mathrm{m}^{2}$ in day and 203 sunlight hours.

It can be clearly seen that the use of solar energy to supply electricity for public lighting in Hanoi can be exploited. However, according to [17], to be available for effective exploitation, it is required that the total radiation potential must be more than $3.35 \mathrm{kWh} / \mathrm{m}^{2}$ in a day and the total average sunlight hours must be more than 150 hours in a month. Thus, the current potential for solar energy in Hanoi has just reached the threshold for effective exploitation. But besides the economic efficiency in the exploitation of solar PV applications, the other benefits such as environmental impact, urban beauty, and social orientation should be considered.



Figure 3: Monthly average of daily solar irradiation in Hanoi

\section{Power Supply Models Using Solar Energy for Public Lighting}

Some power supply models using solar energy can be exploited and used for the public lighting system [19], such as the independent power supply model using solar energy (Model 1), grid- 


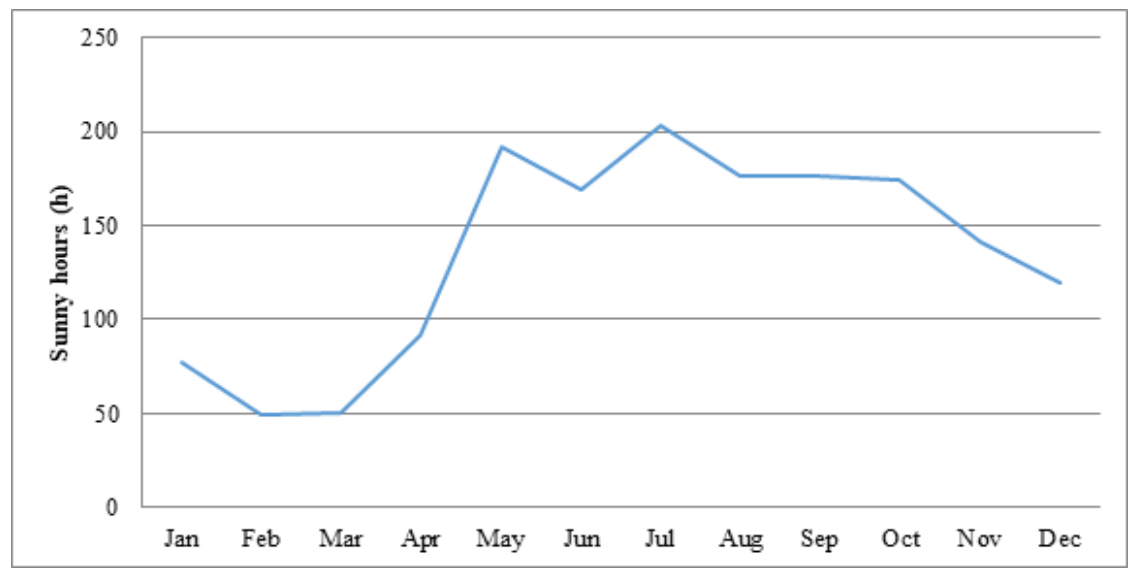

Figure 4: Monthly average of sunny hours in Hanoi

connected power supply model using solar energy with storage (Model 2), and grid-connected power supply model using solar energy without storage (Model 3).

In the independent power supply model, the power is supplied $100 \%$ from solar energy [19] (Figure 5). The DC electricity from the solar PV system is stored into the battery through the $\mathrm{DC} / \mathrm{DC}$ converter, then fed to the AC load by the DC/AC inverter.

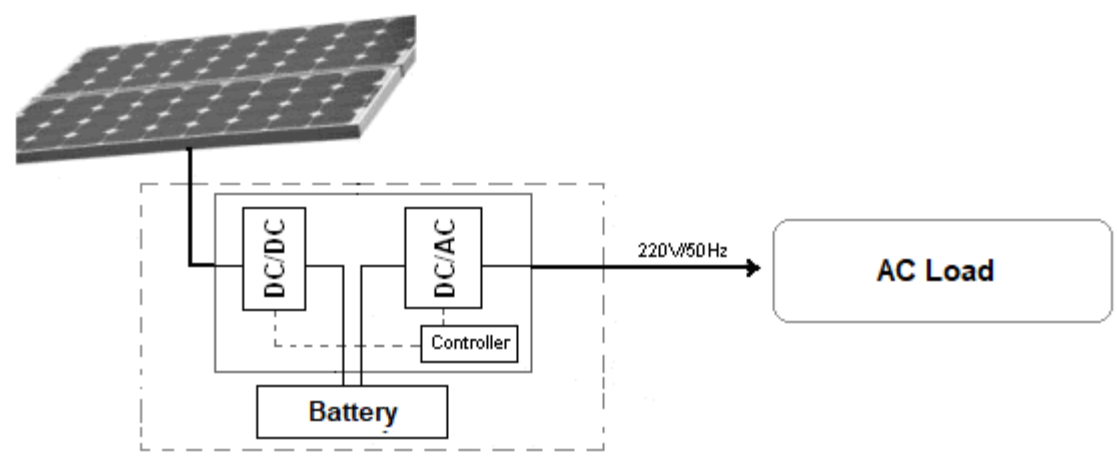

Figure 5: Independent power supply model

The grid-connected power supply model with storage is a combination of solar power and national grid power [19] (Figure 6). The power from solar energy is the main source and the power from the grid is the supplementary source. The power from the solar PV and the grid (in case of the power from solar PV insufficient) is stored into the battery and then supplied to the AC load. If there is excess power from the solar PV system, this excess power will be supplied to the grid through the inverter.

The grid-connected power supply model without storage is similar to the model using solar energy with storage [19] (Figure 7). The power from the solar PV system is injected to the grid through the inverter. And the power to the load is supplied by the grid, with a net power consumption amount of W2-W1. 


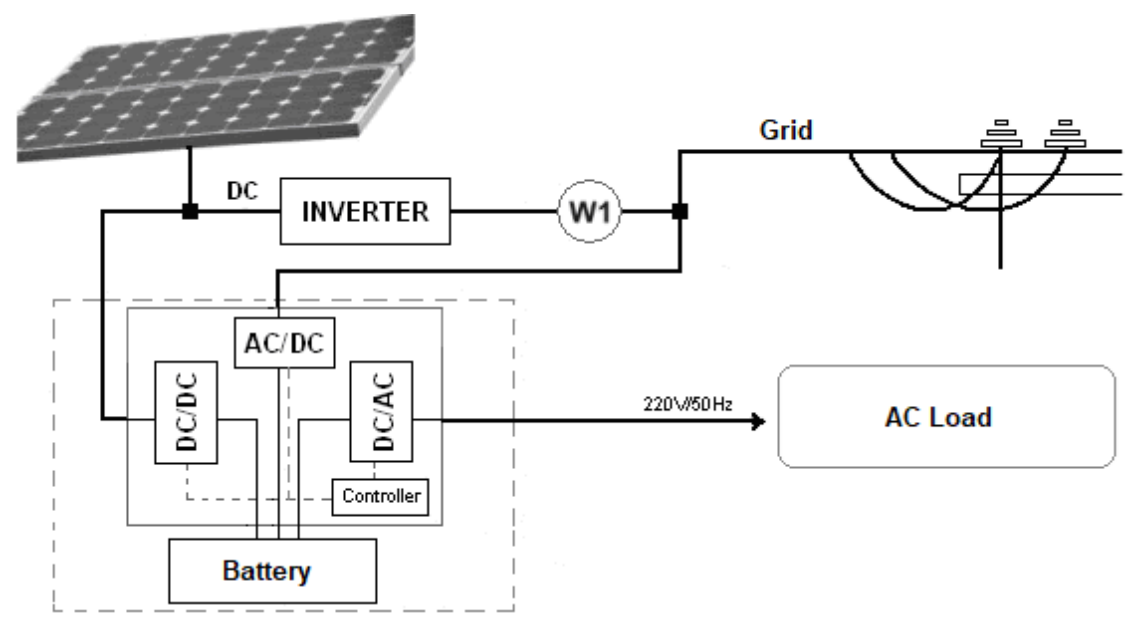

Figure 6: Grid-connected power supply model with storage

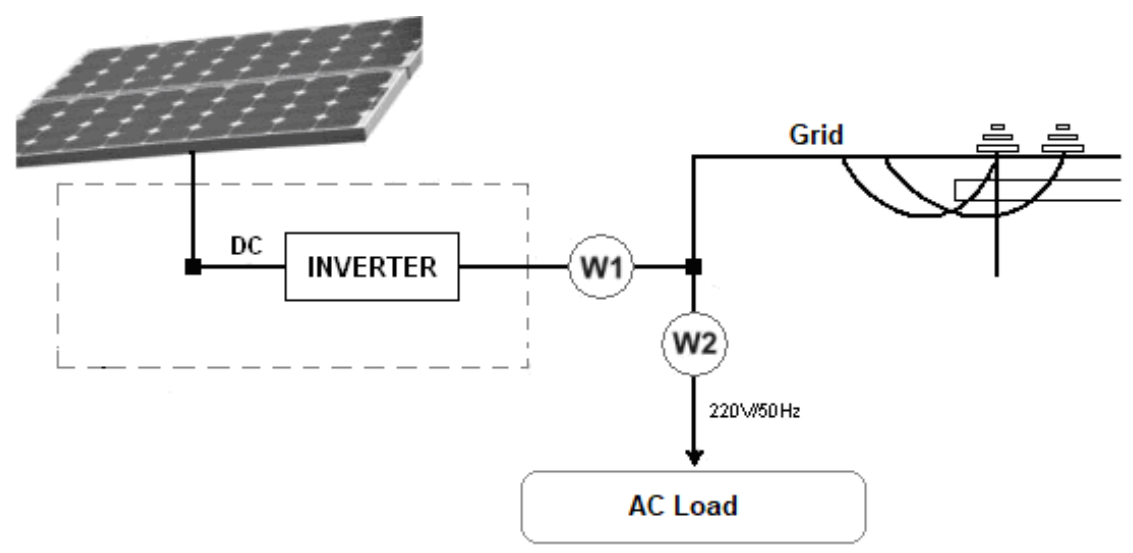

Figure 7: Grid-connected power supply model without storage

\section{Feasibility Analysis of Solar Power Supply Models for Public Lighting IN HANOI}

The public lighting lights in Hanoi have many different power levels, the authors have chosen the lights which are quite common in Hanoi with a consumption power of $150 \mathrm{~W}$ and an operation time of 12 hours/day (from $6 \mathrm{pm}$ to $6 \mathrm{am}$ ), to analyze the feasibility of a solar power model for public lighting in Hanoi. The total initial investment cost includes installation costs and equipment such as PMT, battery, DC/DC converter, DC/AC inverter, controller, etc. In order to ensure adequate power supply for the selected load [20], the models are calculated and designed with the parameters shown in Table 1.

Independent power supply model: The efficiency of this model can be clearly seen as it uses $100 \%$ solar energy for public lighting, without any electricity from the grid. Besides, the system is simple to design and install, suitable for existing public lights. This model also ensures a reliable power supply due to its storage system (battery). The DC/AC inverter in the system allows for a steady supply of voltage, in order to ensure that the lights are not operated at voltages that are either too high or too low. However, at more than 2000 USD, the investment cost for this model is 
Journal of Asian Energy Studies (2021), Vol. 5, 14-21

Table 1: Parameters of solar power supply models for the public lighting in Hanoi

\begin{tabular}{lccc}
\hline & Model 1 & Model 2 & Model 3 \\
\hline Tilt angle of solar PV module (o) & 30 & 30 & 30 \\
Direction of solar PV module & South & South & South \\
Power demand of selected light (W) & 150 & 150 & 150 \\
Installed solar PV capacity (Wp) & 1280 & 1280 & 150 \\
Storage capacity (Ah) & 412 & 206 & 0 \\
Total initial investment costs (USD) & 2119.06 & 1915.35 & 183.88 \\
Total energy saved in a year (kWh/year) & 657 & 657 & 283 \\
Total power into grid in a year (kWh/year) & 0 & 659 & 940 \\
\hline
\end{tabular}

quite high. In addition, because the calculation and design of this model is based on the data of the month with the lowest radiation, there will be an excess of power produced in other months leading to wastage, the inability to fully use the solar resources.

Grid-connected power supply model with storage: It can be seen that the efficiency of this model is similar to the independent power supply model. In addition, the system can supply additional electricity to the grid (excess power from the solar PV system), thereby leading to a full use of solar resources. However, the investment cost for this model is quite high, around nearly 2000 USD. The design and installation of the system are also quite complicated, because it must simultaneously ensure stability and reliability in supplying electricity for load and to the grid.

Grid-connected power supply model without storage: This model is calculated and designed based on the benefits of investment costs, adapting local economic conditions, aesthetics, environmental factors, etc. The efficiency of this model is clearly visible, the initial investment cost is much lower than the two other suggested models. Moreover, this model is completely suitable for the existing lighting system, ensures aesthetics, and fully uses the solar resources. In addition, structure of this model is quite simple and more convenient than the other two models. However, this model depends entirely on the grid, so the system cannot avoid electrical surges as well as voltage fluctuations which can be either too high or too low. This can lead to reduced life of the equipment and can impact the light output.

\section{CONCLUSION}

As discussed above, it can be seen that each solar power supply model has its own advantages and disadvantages. Therefore, the application of these models depends greatly on the potential of solar resources, economic potential, and developmental orientation in the locality. The installation and using of these models is quite flexible, its allows for renovation and upgrading the existing public lighting system, or having a completely new lighting system installed. These models are applicable for street lighting, highways, harbors, airports, warehouses, parking lots, industrial parks, town squares, etc. Based on the analysis of the three models, as well as the economic potential and developmental orientation in Hanoi, the authors recommend using the grid-connected power supply model using solar energy without storage. This model has outstanding advantages that are suitable for Hanoi, including ensuring aesthetics, fulfilling environmental factors, and low investment costs. 


\section{REFERENCES}

[1] Makumbe P, Weyl DK, Eil A, Li J. Proven Delivery Models for LED Public Lighting: Synthesis of Six Case Studies. World Bank Group, 2016.

[2] Global Smart Street Lighting \& Smart Cities: Market Forecast (2019-2028). Northeast Group, 2019.

[3] Makumbe P, Weyl DK, Eil A, Li J. Proven Delivery Models for LED Public Lighting: Delivery Model in Central and Northwestern India. World Bank Group, 2016.

[4] Makumbe P, Weyl DK, Eil A, Li J. Proven Delivery Models for LED Public Lighting: Joint Procurement Delivery Model: Ontario, Canada. World Bank Group, 2015.

[5] Makumbe P, Weyl DK, Eil A, Li J. Proven Delivery Models for LED Public Lighting: Lease-to-Own Delivery Model in Guadalajara, Mexico. World Bank Group, 2016.

[6] Makumbe P, Weyl DK, Eil A, Li J. Proven Delivery Models for LED Public Lighting: Municipal Financing Delivery Model in Quezon City, Philippines. World Bank Group, 2016.

[7] Meyer M, Maurer L, Freire J, De Gouvello C. Lighting Brazilian Cities: Business Models for Energy Efficient Public Street Lightning. World Bank Group, 2017.

[8] Inadequacies in urban lighting in Vietnam. The Nhan Dan, 2019. https://nhandan.com.vn/baothoinay-dothi/bat-cap-chieu-sang-do-thi-376640.

[9] Vietnam Energy Efficiency Public Lighting. United Nations Development Programme and Vietnamese Academy of Science and Technology, 2011.

[10] Resolution 1210/2016/UBTVQH13 on Urban Classification. The National Assembly Standing Committee, 2016.

[11] Circular 22/2019/TT-BXD of National Technical Regulations on Construction planning. Ministry of Construction, 2019.

[12] National Technical Regulation QCVN 07-7:2016/BXD on Technical Infrastructure Works Lighting. Ministry of Construction, 2016.[-20pt]

[13] Allery TA, Martino A, Org M, Begay S. Solar Street Lighting: Using Renewable Energy for Safety for the Turtle Mountain Band of Chippewa. U.S. Department of Energy, 2018.

[14] Arshad MS, Ain MF, Ishak D, Rahman ALA, Nazri AS, Abdullah MN, Kaharuddin S, Hussin R. Study on and the implementation of solar powered street lighting in SEEE, USM. AIP Conference Proceedings 2017:1892.

[15] Sutopo W, Mardikaningsih IS, Zakaria R, Ali A. A model to improve the implementation standards of street lighting based on solar energy: A case study. Energies 2020:13:630

[16] Decision 1874/QD-TTg on Approval of Development Orientation of Urban Lighting in Vietnam up to 2025. Government of Vietnam, 2010.

[17] Hoat DD, Tuyen TK, Hang LTT, Thanh NV, Thanh TQ, Quoc TH, Minh NT. Research Overview of New and Renewable Energy in Vietnam and Development Orientation. Vietnam Academy of Science and Technology, 2007.

[18] Polo J, Martínez S, Fernandez-Peruchena CM. Maps of Solar Resource and Potential in Vietnam. Vietnam Ministry of Industry and Trade \& Spanish Agency for International Development Cooperation, 2015.

[19] Jäger K, Isabella O, Smets AHM, van Swaaij R and Zeman M. Solar energy - Fundamentals, Technology, and Systems. Cambrdige, UIT Cambridge, 2014.

[20] Khuong PM, McKenna R, Fichtner W. A cost-effective and transferable methodology for rooftop PV potential assessment in developing countries. Energies 2020:13:2501.

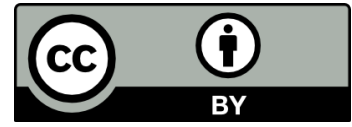

(C) The Author(s) 2021. This article is published under a Creative Commons Attribution (CC-BY) 4.0 International License. 